\title{
Space as a resource: West Berlin's impossible sites
}

\author{
V. M. Carlow \\ Institute for Sustainable Urbanism, \\ Technische Universität Braunschweig, Germany
}

\begin{abstract}
Because of its containment by the Wall during the years 1961-1990, West Berlin experienced a strict limitation on its physical boundary. This condition, plus the transition from an industrial to a service-oriented economy characteristic of this period, gave rise to a particular experimental urban culture. Based on an attitude of treating space as a scarce resource, this culture led to the opening of sites with very difficult conditions for development, for example those close to major infrastructural arteries. This paper examines these "impossible" sites - sites, which under conventional circumstances would have been considered too difficult or unmanageable for development, but which in West Berlin were used for development of various kinds. Presented as case studies, these sites reveal experimentation with mix of functions, formal architectural language, public space typologies, and technical strategies to deal with adverse environmental hazards, such as noise and air pollution. In addition, innovation in urban policies, such as the International Building Exhibition program, also emerged. While cities today may not face the particular conditions as faced by West Berlin during its period of containment, space is indeed increasingly scarce in rapidly urbanizing regions, and a shift in attitudes and thinking about urban space is critical for sustainable development and planning. The case of West Berlin offers important lessons on how users and policies can adapt creatively to conditions of scarce space. The paper concludes with hypotheses about opening up as yet "impossible" sites for development in other contexts, and how challenges in accessibility and perception could be overcome to make these spaces "productive."

Keywords: West Berlin, urban culture, urban development, urban policies, space as resource, density, sustainable development, sustainable planning.
\end{abstract}




\section{Introduction}

In today's rapidly urbanizing world, space is an increasingly scarce resource, especially in already urbanized areas. The use and management of space in urban contexts play a major role in sustainable urban development.

The case of West Berlin between the years 1961-1991 offers valuable insights into how space may be used resourcefully and innovatively, from the design and policy perspectives. This period was a period of physical containment for West Berlin, a time in which a modern, economically viable West German city could not physically expand beyond a clear and indelible demarcation, namely, the Berlin Wall. While West Berlin during the aftermath of the Second World War experienced an overall decrease in population, factors such as changes in housing standards, modernization of facilities and urban infrastructure, and shifts in demographics and lifestyles put pressure on the spatial requirements of the city. In West Berlin, physical expansion was limited to the areas within the Wall. After more large-scale settlements had been constructed at the city fringe, interventions had to become smaller, and take place in the inner city. As a result, the city had to come up with new ways to find and use space within its limits, thereby developing a culture of negotiating its needs around its physical containment.

From this position comes the idea of "impossible sites," by which I mean actually possible. In West Berlin, the scarcity of space led to the opening of sites with very difficult conditions, for example sites close to major infrastructure arteries. In this paper, I will discuss the culture and its particular will to experiment (Experimentiergeist), which allowed for such "impossible sites" to be developed, and present case studies of such sites along the S-Bahn ring and inner urban highway. While all examples are located in "central" places around West Berlin, these sites nonetheless remained unused for a long time before the solutions under discussion were enacted. With these examples, I will detail how the scarcity of space led to innovations in architectural design, material usage, formal layout, mix of functions, and contributed to an urban culture of density. It should be noted, however, that this attitude of treating space as a scarce resource does not preclude the value of voids, or open space, in the urban context, of which West Berlin had plenty, and out of which emerged a significant culture of temporary and experimental uses which characterizes Berlin even today. I will conclude by speculating on how this shift in thinking toward the idea of space in the urban context as a limited and valuable resource may be pushed in policies, and recommend design principles that can promote spatial resourcefulness and bring about higher quality of life for the inhabitants.

\section{West Berlin as a contained city}

\subsection{Contained economy}

To give the context for how the culture of Experimentiergeist emerged in West Berlin, I will provide a short overview of the economic conditions of the city 
during this period. After the war, Berlin lost much of its industrial, political, and commercial functions. Many companies formerly based in Berlin, like Siemens or AEG, relocated their headquarters towards the West, to cities like Munich or Stuttgart, and in the Ruhr Area, by then the main arena of industrial activity. Many at the time feared that West Berlin was moving steadily towards the periphery of a booming West German economy [1].

In retrospect, it can be said that West Berlin simply de-industrialised a few years earlier than other cities. Hillenbrandt shows how successive West Berlin governments since 1949 sought to answer the question of how to keep West Berlin viable given such trends: one important response was to ensure that the federal government provided adequate funding to keep the city running. This meant direct subsidies to the city's budget that in some years amounted to over half the total revenue. Karl Schiller, the Minister of Economy and Finances between 1966 and 1972, designed an economic policy that foresaw a considerable increase in economic assistance given to West Berlin by the federal government, called 'push and pull': pulling capital to the city and pushing investment and thus economic growth. This policy included substantial loans, tax allowances for employees and employers, and a negative tax (a nontaxable rebate) of 20 to $30 \%$ for fixed investments of businesses investing in West Berlin, especially those establishing production facilities [2]. There were other economic benefits for West Berlin residents in the period immediately after the Wall went up: a 'jitters bonus' was given to help people pay the extra costs for vacations outside Berlin. Tax incentives were given for sending packages with consumer goods to East German relatives [2].

On 12 August 1961, the day before the Wall was built, West Berlin had a population of 2.2 million, a labour force of 1.015 million, and a Gross National Product (GNP) of about Deutsche Mark (DM) 30 billion. According to Merrit, the Wall did not have an immediate effect on economic development: even though there was a short-term turbulence, already in 1963 the rate of GNP growth was nearly as high as in the Federal Republic of Germany (FRG) [2]. In 1964 and 1965 West Berlin displayed growth rates of 6.4 and 5.7\% respectively, the latter being even higher than that of the FRG [2]. However, the containment did significantly affect the workforce. A loss of 50,000 workers who lived in East Berlin and crossed the border every day to work in West Berlin - the 'border commuters' - was noticed immediately [2]. During the following years, a remarkable surge in productivity compensated for that loss, according to Gerhard Mensch: in an era when technology replaced labour intensive forms of production, the absence of excess labour in West Berlin, relative to other parts of the European Community, may have been an actual advantage for West Berlin, since it forced companies to innovate. The productivity figures after 1961 support this evaluation [3]. The city's economy faced more problems connected to the loss of people, since the migration from East Germany, which had brought mainly young and/or well educated people to the city, had stopped. The age structure indicated that the workforce would decline even more in the future [4]. Hence, since the beginning of West Berlin's containment, policy makers 
considered the attraction of qualified workers to the city as fundamental to future economic development.

According to the German Institute for Economics, in the 1960s three main economic trends could be observed: (A) The size of the population remained almost stable. At the beginning and the end of the decade West Berlin had almost 2.2 million inhabitants. It lost 100,000 Germans due to the age structure, but it gained 100,000 foreigners. (B) There was a decline in labour force from about one million to 930,000 . In comparison, in the FRG the size of the workforce remained almost the same. (C) The growth rate of GDP was a little bit more than $4 \%$, whereas in the FRG it was a little bit less than $5 \%$ - a difference of $0.5 \%$ [5].

In the 1970s the situation changed. At first, the Quadripartite Agreement triggered excessive hopes in West Berlin, even though the economic parameters pointed to a more modest situation according to the German Institute for Economics' indices: (A) the outflow of population was greater than the inflow, which resulted in a net loss of 15,000 workers, or about $2 \%$ of the overall workforce. (B) Neither the manufacturing sector nor other producers established new firms, nor did they create many new jobs [5]. In the mid-1970s the decline in population could not be stopped. $15 \%$ of the city's population was under 15 , and 22\% older than 65 (in the FRG: $23 \%$ and 13\% respectively). These figures were a clear indication of an aging population. The population dropped by 200,000 to about two million; and the city lost roughly 100,000 jobs in that decade [4]. In the mid-1970s the FRG experienced an economic slump as well (the first oil crisis). While the growth rate was $2.8 \%$ in the FRG, it was only $2.1 \%$ in West Berlin - a remarkable difference of $0.7 \%$, meaning West Berlin had a growth rate of only $75 \%$ of that of the FRG [2]. Towards the end of the 1970s, however, West Berlin presented a more optimistic picture: the loss of jobs was slight - roughly the same in West Berlin as in the FRG. The gap in economic growth narrowed. At the onset of the 1980s the city had a population of some two million and a work force of 835,000 , as compared to one million in the 1960s. The GNP in 1980 stood at DM 35 billion. West Berlin had 3.4\% of both the FRG's workers and GNP [2] - a balanced situation.

\subsection{Policies: IBA 1984/87}

What did this mean in the planning sector? The economic changes West Berlin experienced during its containment seem to have been not much divorced from the major structural transformations the rest of the country was experiencing at the time, though it could be argued that the transition was faster and more pronounced than in other German cities at that time. These transformations also represented the context within which planning in West Berlin had to take place. The linkages with the FRG made West Berlin economically dependent. It flourished or stagnated as the economy of the FRG flourished or stagnated. In that sense, West Berlin was no exception to other cities. Yet, the containment imposed severe restrictions on the physical expansion of the city. It did not made life impossible, or even less economically viable than elsewhere, but it challenged traditional forms and formats of planning and architecture. 
As West Berlin shifted from a more industrial-oriented to a more service- and knowledge-oriented economy, the urban development policies of the city administration responded to that shift. West Berlin was forced to enter the international competition for more qualified workers as early as 1961. Therefore, policy makers in West Berlin focused on policies targeted at attracting people to the city, and improving the quality of life in the city. The construction of Kulturforum with New National Gallery (Mies van der Rohe) and other flagships of high culture attest to this.

The International Building Exhibition (in German: Internationale Bauaustellung, or IBA), a temporary and experimental set-up for planning, with a particular focus on housing, demonstrates this policy focus. To give an indication: in the $1980 \mathrm{~s}$, approximately $10 \%$ of the one million dwelling units in West Berlin had no bathrooms [6]. In 1984/87 Berlin celebrated its second IBA, and massive investments to raise the quality of the housing stock were undertaken. This IBA was targeted on the one hand the upgrade and improvement of the existing housing stock of the industrial era ('IBA old'), and on the other hand the construction of contemporary housing ('IBA new'). Social housing projects were planned not only on newly claimed land, but also as infills in the perforated urban fabric, thereby establishing the theoretical frameworks of 'critical reconstruction' (in German: kritische Rekonstruktion) and 'careful renewal' (in German: behutsame Stadterneuerung) that was for twenty more years the physical Leitbild for the city's architectural re-unification after 1989.

The goal of such careful renewal processes was to maintain the existing building stock of old buildings, instead of demolition and new construction, where possible. Also important was the idea that the renewal process should allow residents to stay in their homes and neighbourhoods after the renewal project. Social networks were considered essential to the process of urban development, and early examples of participatory planning methods were implemented. In that sense, careful renewal was a first counter strategy to gentrification - a term then not yet widely known or used - developed in West Berlin, and an important policy innovation. It is important to note: most of the projects were located in Kreuzberg, one of the poorest but also most diverse and vibrant districts of the city, even today. Projects in this framework also included improvements of recreational facilities to match levels in Hamburg or Munich, with the goal to attract more skilled people and workers.

\section{West Berlin's impossible sites: case studies}

With its limitations in physical growth, coupled with the relative stability in social and economic conditions during its period of containment, West Berlin faced a unique problem of how to modernize and grow within its limitations. Infrastructural upgrades, such as the introduction of the inner-city Autobahn, as well as the intensification of the public transportation network (U-Bahn and S-Bahn), produced a densification of the city, as well as many difficult, left-over spaces near or around the traffic network, such as: spaces occupied by inner 
urban highways, large roundabouts, spacious intersections, highway exits, and slip roads.

Under the planning paradigm of the 'car-friendly city' - which was itself derived from architect and urban planner Hans Bernhard Reichow's 1959 The car-friendly city - a path out of traffic chaos [7] - alternative flows of traffic were subordinated to the car in many central areas of the city. Two remarkable examples of 'car-friendly' planning are the intersections 'An der Urania' and the square 'Ernst-Reuter-Platz'. Both traffic spaces are approximately $300 \mathrm{~m}$ in diameter and spatially dominated by four- or six-lane roads that are flanked by semi-high-rise housing and important public institutions, such as university institutes or company headquarters. The design of both spaces originates from the early 1960s. Both are conceived from the perspective of the car, based on a rapid change of perspective while floating undisturbed through the city on four wheels. The preferred mode of presentations of these city spaces can only be an aerial view. From a pedestrian point of view the space cannot be grasped, nor with the standard lens of a camera. Even though pedestrians crossing the road are not forced into tunnels or onto bridges, the dimensions of these intersections and roundabouts are geared towards car traffic. In Ernst-Reuter-Platz, while a car requires the time of one traffic light interval to cross the intersection, a pedestrian or cyclist has to stop at least three times. Ernst Reuter Platz is actually not a square but a gigantic roundabout. In the middle is a fountain that lay idle for many years. The dimensions of these traffic spaces are similar to the much criticised socialist planning in East Berlin. Both were recently renovated. However, how the 'car-friendly city' was challenged during the city's containment will be demonstrated by the following three examples.

\section{1 "Traffic arcade"}

Kaiserdamm is a boulevard that was built according to the orders of Kaiser Wilhelm II. It was opened in 1906. The avenue is the westward extension of Unter den Linden and Straße des 17 Juni. Where the highway towards Hamburg underpasses Kaiserdamm, streams of bypassing traffic are reflected in a large mirror. The architect Jürgen Sawade worked on the design of a building for this plot for ten years from 1983. Similar to the site of Kollhoff and Timmermann's screen railway apartment building in Berlin Wilmersdorf [8], this plot is heavily burdened by traffic. Not only does the highway E55 pass under Kaiserdamm, the rail and the S-Bahn circle line run parallel to the site. The project, "Traffic Arcade", meets the conditions of heavy traffic at one of Berlin's major radial roads.

Towards the highway, Sawade works with a screen in order to shield the building from the traffic emissions. A glass arcade - then a Berlin novum parallel to the road and railway, mirrors the spaces of flows into the building as an internal system of secondary spaces of stairs and hallways. Before the large glass façade was trivialised by mirror glass film, users of the building could see trains, cars and people moving parallel to themselves. Divided from the building at Sessener Straße, the residential and office building is functionally differentiated. All the apartments are oriented towards the courtyard, and 
therefore largely protected from noise and pollution. The offices are located towards Kaiserdamm. Sawade has chosen an architectural strategy of functional zoning and disguise. It was conceived under the condition of a modest void phobia that put even heavily traffic burdened sites on the agenda of planners and architects.

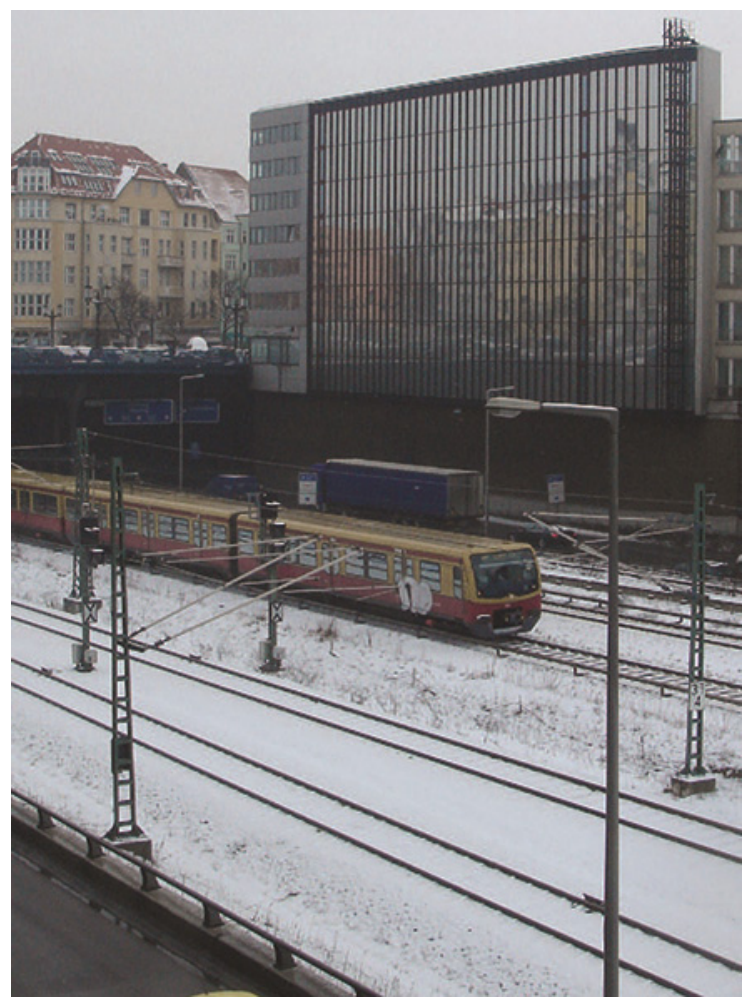

Figure 1: "Traffic arcade". Residence and office building in Berlin. Owner: undisclosed. Photograph by the author.

\subsection{Mitigator}

The site at "Germany's most frequented highway segment" [9] was considered irreclaimable at the time the international competition was called for a new office building, at Kronpinzendamm. The Berlin architects Léon and Wohlhage proposed a seven-storey solitary cantilevering over a six metre air space above the highway curtilage. The column-free floor space comprises $7,500 \mathrm{~m}^{2}$ per floor over the triangular site that is - as a residual space - shaped by the geometry of the highway. From the highway the building is marked by its dynamic curved glass façade that seems to float in the air when seen from afar. 
In order to cope with the heavy noise and gas exhaust emissions, the building has a double skin façade, which is aired from the roof to guarantee natural ventilation and a natural indoor climate without the need to open the windows to the noisy street. This among other aspects rendered the building 'ecological' in its time. Furthermore, it can be argued that the building mitigates some of the downsides of a proliferation of traffic networks that the 19th century neighbourhood behind the building was facing. It shields the street on its backside from the noise; it reorganises the urban space that had before ended in an impasse; it offers a publicly accessible pocket park; and it provides additional parking spaces in an underground parking lot.

Not far away, the International Congress Centre (ICC) (1973-79, architects Ralf Schüler, Ursulina Schüler-Witte) is located. Like the office building at Kronprinzendamm, it is located in a heavily traffic-burdened street. However, different from the office building, the centre turns its back to the highway. It is constructed in a house-in-house concept to mitigate the vibrations of the highway that also has an underpass through the building. With a capacity of 20,000 seats,

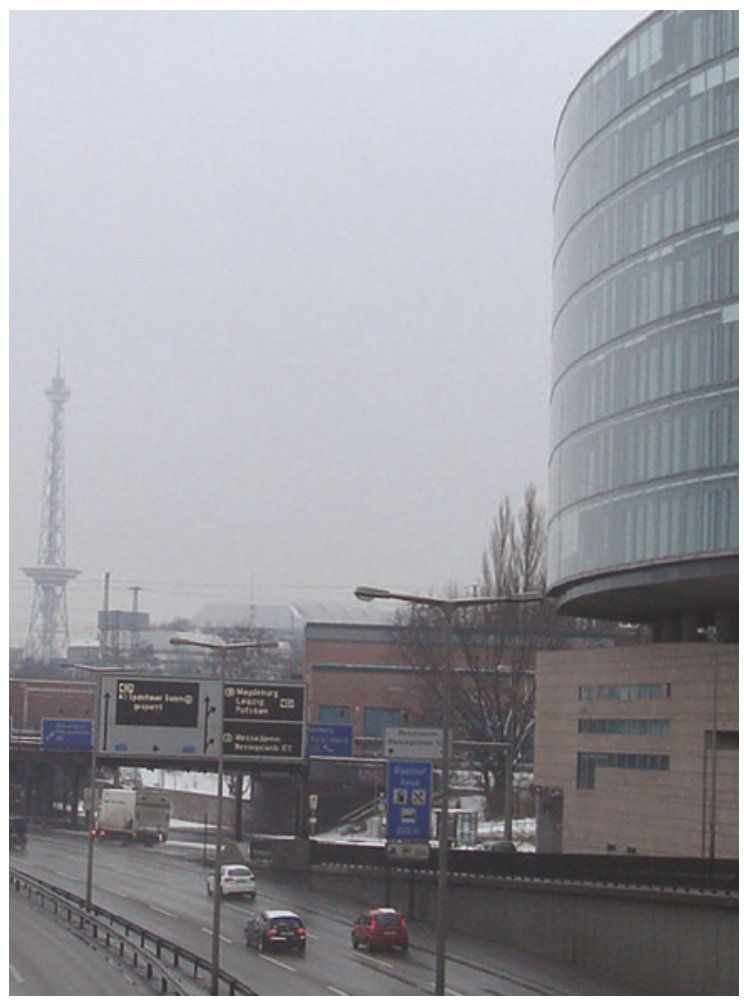

Figure 2: Mitigator. Location: Berlin Charlottenburg, office building at Kronprinzendamm 15. Built 1989 (competition)-1994. Architects: Hilde Léon und Konrad Wohlhage. Owner: Mübau Berlin [9]. Photograph by the author. 
the centre is fully climatised. In contrast to the Mitigator, this building mitigates the hazards of its location by ignoring it, based on the technological possibilities of its time [9].

\subsection{Soft soundscape kindergarten}

Another aspect of mitigation to be addressed is acoustical. Both airports in West Berlin, Tegel and Tempelhof, were inner urban airports. Since Tempelhof was located inside the city, and Tegel at the fringe, an estimated 300,000 people were affected by noise and the visual impact of take-offs and landings of airplanes daily. Since in the context of contained West Berlin the airports and their emissions could not be outsourced to locations outside the city, it became necessary to deal with their impact within the urban realm.

One example for mitigating the noise and visual impacts of airplanes is a kindergarten designed by the architects Zillich and Engelmann, which I call 'Soft Soundscape Kindergarten'. The facility is located right under the approach path to Tegel Airport. The noise impact in residential buildings is often mitigated by integrating isolating windows into the architecture; however, the quality of the outdoor spaces, like gardens or parks, cannot be improved by such measures. For the daycare facility, which like schools and sporting facilities depend on good outdoor spaces, the architects suggested a wing cantilevering over the building and parts of the outdoor playground. The wing reflects the noise, so that the spaces in its shadow are protected. Since the experience of noise is a holistic experience - in a person's perception the disturbing sound of cars may be amplified by their visual impact and smell - the wing also visually hides the planes.

In particular with view to the increasing traffic volumes, this is a good early example of how the impact of air traffic can be mitigated in an urban context. Rather than be dismissed as useless, these spaces near infrastructure can also function as a separator and a connector. In West Berlin, the infrastructural

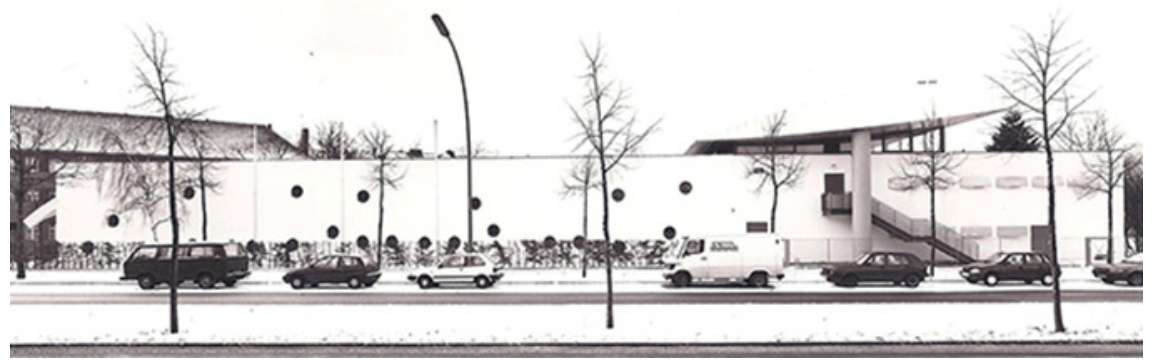

Figure 3: Location: Berlin Reinickendorf, Lindauer Allee 51-53. Built 1989. Architect: Zillich and Engelmann. Owner: The City of Berlin. Photograph by Uwe Rau. Courtesy of Klaus Zillich. 
networks not so much expanded but rather densified under the spatial constraints [8]. The spatial constraints in combination with proliferating infrastructural networks led to the emergence of new typologies and hybrids of buildings at the borders of these infrastructure networks, utilizing and making productive a new typology of building plots.

\section{Conclusion: opening up further impossible sites}

During the time of containment in West Berlin, a tendency towards small- or micro-scale interventions could be observed. Increasingly, economically less feasible sites were opened for development, for example sites located nearby major infrastructure. Preference was given to renovation and conversion, rather than new construction. There were no inflationary land prices that could have caused a severe void phobia in West Berlin, but the shortage of land was felt, and there was a strong inclination to fill gaps in the historical urban fabric, rather than use new land for development.

Some of the sites that were opened up during the time of spatial containment can be and were considered 'difficult' or even 'impossible.' These sites were far from the classical ideals of having clean air, abundant greenery, plenty of sunlight, and being free of noise pollution, but instead, located next to the proliferating infrastructural networks. Because of its culture of experimentation at the planning and architectural levels, in West Berlin, spaces for living and working penetrated into various urban conditions, and thereby set up new relationships with its surroundings. The possibilities for urban dwellings expanded even as the space in the city centre became smaller. Historically strong separation between specialisations, such as civil engineering (infrastructure) and architecture (housing) was blurred in the realisation of some of the abovementioned examples.

With the global trend of ever-expanding networks, an enormous amount of surplus spatial resources in the form of under-infrastructure, next-toinfrastructure, or on-top-of-infrastructure spaces are available. At a time in which accessibility is a cost factor, these could be the privileged central places of future urban development. When the elevated highways become the train viaducts of the future, we have to consider how we want to use them.

An urban culture of accepting limits, the idea that space is a scarce resource, and experimental, innovative attitudes geared toward finding radically new responses to these limits addresses the larger question of how cities can be built to be more sustainable from environmental, sociological, and economical perspectives. For this, an adjustments of building regulations is required, namely, that sites be considered on a case-by-case basis. I have shown that in West Berlin, this led to buildings and new spatial configurations that would not have been possible following conventional standards or regulations. This is a valuable hint with regard to the quest for a more sustainable development in cities today: above all, the regulatory framework must be transformed. Often, it is simply not allowed by existing building regulations to build denser, or to hybridize functions, even though the impact on the surrounding city would not necessarily 
be harmful. What is thus required to go forward toward resourcefulness and creativity in spatial thinking is a new attitude of openness in the negotiation of standards.

\section{References}

[1] Merrit, R.L. “The Lost Centre: Dispersing Berlin's Capital City Functions, 1945-1978," in Western European Cities in Crisis, Michael C. Romanos, Ed. Lexington, MA, USA: Lexington Books, pp. 185-202, 1979.

[2] Hillebrand, M., Living with the Wall; West Berlin, 1961-1985, Richard L. Merritt and A.J. Merritt, Eds. Durham: Duke University Press, pp. 104-105, p. 135, pp. 137-138, p. 142, pp. 194-195, 1985.

[3] Mensch, G., "The Economic Perspectives for Berlin," in The Future of Berlin, Martin J. Hillenbrand, Ed. Montclair, New Jersey: Allanheld, Osmun \& Company, pp. 153-228, 1980.

[4] Statistisches Landesamt Berlin, Berliner Statistik. Die Wohnbevölkerung nach Alter, Geschlecht, Familienstand und Beteiligung am Erwerbsleben in Berlin (West), 1958-1983, 1983-1990.

[5] Deutsches Institut für Wirtschaftsforschung, Lange Reihen der vierteljährlichen volkswirtschaftlichen Gesamtrechnung für die Bundesrepublik Deutschland und Berlin (West). Berlin, Germany, 1982.

[6] Bodenschatz, H., Platz frei für das neue Berlin! Berlin, Germany: Transit, pp. 186-199, 1987.

[7] Reichow, H.B., Die autogerechte Stadt-Ein Weg aus dem Verkehrs-Chaos. Ravensburg: Maier, trans. by author, 1959.

[8] Carlow, V.M., "Limits: Urban Density and Mobility Networks in West Berlin during the Period of Containment," sustainability, vol. 6, pp. 74527465, ISSN 2071-1050, Oct. 2014.

[9] Wörner, M., Mollenschott, D., Hüter, K. H., and Sigel, P., Architekturführer Berlin, 6th ed. Berlin: Dietrich Reimer Verlag, p. 284, 2001. 